\title{
Self-Esteem and Visual Self-Presentation on Facebook among Chinese Undergraduate Students in A Public University in Malaysia
}

Michelle Tiong Wen Hui and Lee Yok Fee

To Link this Article: http://dx.doi.org/10.6007/IJARBSS/v11-i19/11723

DOI:10.6007/IJARBSS/v11-i19/11723

Received: 13 October 2021, Revised: 17 November 2021, Accepted: 25 November 2021

Published Online: 19 December 2021

In-Text Citation: (Hui \& Fee, 2021)

To Cite this Article: Hui, M. T. W., \& Fee, L. Y. (2021). Self-Esteem and Visual Self-Presentation on Facebook Among Chinese Undergraduate Students in A Public University in Malaysia. International Journal of Academic Research in Business and Social Sciences, 11(19), 147-157.

Copyright: (c) 2021 The Author(s)

Published by Human Resource Management Academic Research Society (www.hrmars.com)

This article is published under the Creative Commons Attribution (CC BY 4.0) license. Anyone may reproduce, distribute, translate and create derivative works of this article (for both commercial and non-commercial purposes), subject to full attribution to the original publication and authors. The full terms of this license may be seen at: http://creativecommons.org/licences/by/4.0/legalcode

Special Issue Title: Youth and Community Wellness, 2021, Pg. 147 - 157 


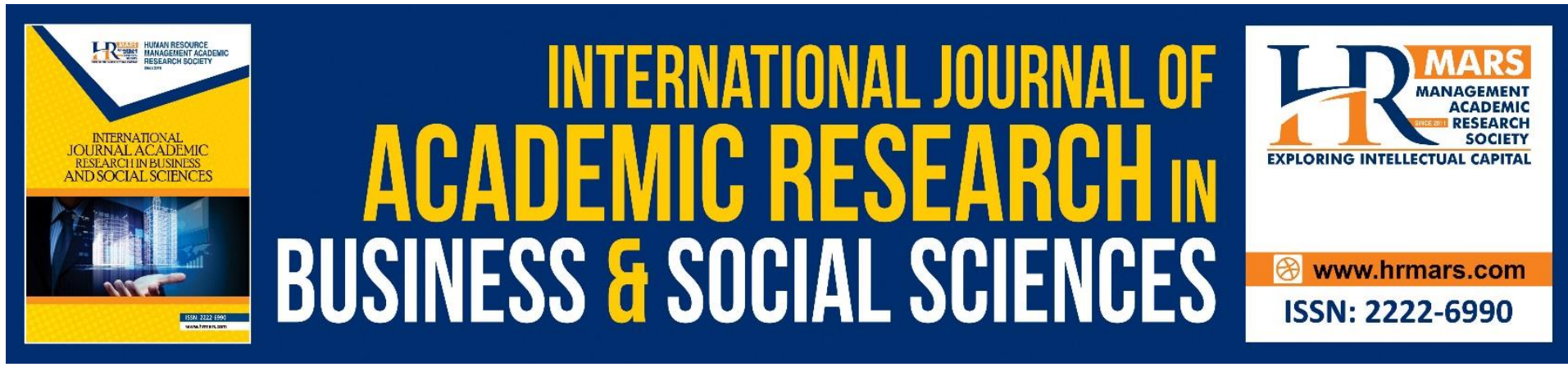

\title{
Self-Esteem and Visual Self-Presentation on Facebook among Chinese Undergraduate Students in A Public University in Malaysia
}

\author{
Michelle Tiong Wen Hui ${ }^{2}$ and Lee Yok Fee ${ }^{1,2}$ \\ ${ }^{1}$ Institute for Social Science Studies, Putra Infoport, Universiti Putra Malaysia, 43400 UPM \\ Serdang, Selangor, Malaysia, ${ }^{2}$ Faculty of Human Ecology, Universiti Putra Malaysia, 43400 \\ UPM Serdang, Selangor, Malaysia. \\ Corresponding Author Email: leeyokfee@upm.edu.my
}

\begin{abstract}
Increasing usage of technologies and internet contributes to an introduction of online social networking sites or social media such as Facebook. Facebook has become a platform for selfpresentation, especially among the youth. This qualitative study was carried out to study description of self-esteem and visual self-presentation among Chinese undergraduate students in a public university in Malaysia. Altogether ten Chinese students from the university were recruited through purposive sampling and interviewed. This study found that high self-esteem students expressed that they are not addicted to Facebook, accept more real-life/known friends and would not "un-tag" unflattering photographs, while low selfesteem students are addicted to Facebook, accept more strangers on Facebook and would "un-tag", hide or even delete the unflattering photographs on their Facebook. This study also discovered that management of students' visual self-presentation on Facebook could be divided into two categories, i.e. selective visual self-presentation and authentic visual selfpresentation. In short, this study gave a big pictures on characteristics of self-esteem, types of visual self-presentation, and reasons for using different types of visual self-presentation besides raising awareness of Facebook addiction among university students.
\end{abstract}

Keywords: Self-esteem, Visual Self-presentation, Facebook, University Students

\section{Introduction}

Nowadays, in conjunction with rapid development in information technologies, almost every part of our lives goes online. For instance, we carry out online shopping, online banking, online education, and online communication. Increasing usage of technologies and internet contributes to an introduction of online social networking sites such as Facebook, Instagram, Snapchat and others. This phenomenon provides a new platform for individuals to present themselves online in a virtual world. Individuals especially young adults present themselves through posting photographs of themselves, writing "status" and sharing "posts" on Facebook. Sharing everything about life is not a weird phenomenon in recent years. This phenomenon brings some social issues like cyberbullying, committing suicide, and catfishing. 
Some people present their ideal selves online to get more attention, especially when "Facebook likes" becomes a measuring tool and represents some impression to others. Some believe that having a lot of "likes" means the person has a lot of friends and is very popular. However, cyberbullying can happen especially when others find out their true self. For example, a girl in China was attacked by internet users when her true, unedited pictures were exposed by her friend. Harsh words filled her Weibo account (SOHU News, 2017). The girl was strong enough to survive the verbal abuse, but some who cannot bear it may commit suicide to free themselves from the pressure.

Committing suicide among youths in Malaysia should be given high attention since the statistics in 2016 showed that committing suicide was the second leading cause of death for youth between the ages of 15 to 29 (Pillay, 2017). There was also increasing evidence that social media could contribute to suicide-related behavior. This happens when someone expresses his or her feelings and posts about suicidal intentions online but he or she receives negative feedback. Furthermore, Yayasan Generasi Gemilang (GG) director of services, Nicholas Foong suggested that unless one has high self-esteem and self-confidence, people will be affected easily by what others say, especially in a negative way (Brown, 2017).

Besides that, "catfishing" which refers to creating false identity online is another issue related to online self-presentation. "Catfishing" appeals to those people who want to create another version of themselves, or an entirely different person altogether that sometimes prompts the victim to then become the aggressor (McDonough, 2014). "Catfishing" also leads to the stealing of others' information and photos. "Catfishing" is mostly used for deceptions especially romance scams (Shaari et al., 2019). In Malaysia, a total of 2,497 cases were recorded in 2016 with losses amounting to nearly RM100 million (Vijaindren, 2017).

Therefore, in view of their close relation to the social prblems mentioned above, selfesteem and visual self-presentation in virtual world or social media are important to be investigated and understood.

\section{Literature Review}

For the academic aspect, related studies were not focused on Malaysians. Moreover, most of them were quantitative researches that studied self-esteem and online selfpresentation. A study carried out by Kim and Baek (2014) was to determine the relationship between selective self-presentation and online life satisfaction, as well as how this relationship was influenced by self-esteem and social trust. From the survey data of 712 Korean online users, they found out that the relationship between selective self-presentation and online life satisfaction becomes weaker among respondents with high self-esteem compared to those with low self-esteem. Selective self-presentation increased online life satisfaction when online users have either low self-esteem or high social trust levels.

In a study to identify the self-presentation of emerging adults on Facebook and the relationship between identity state, psychosocial well-being, and online self-presentation. Michikyan et al (2014) found out that respondents with a less coherent sense of the self and lower self-esteem were more likely to present their false-self on Facebook. A total of 261 participants completed self-report measures of identity state, well-being, and selfpresentation on Facebook in the study.

In addition, Gil-Or et al (2015) studied the characteristics and psychological predictors of false self-presentation on Facebook as another related research. They collected data from 258 Facebook users aged around 20 to 65 years old in Israel. Through ANOVA and SEM analyses, they determined that users with low self-esteem and low trait authenticity were 
more likely to present a false Facebook self. Besides that, several cases (7.5\%) with large gaps between the true and false Facebook self were detected.

With a sample of 156 young Tinder users recruited in the Netherlands, Ranzini et al (2016) carried out research to assess how Tinder users present themselves and explore the impact of their personality and their motives of using Tinder. According to their findings, they found out that self-esteem had a negative effect on ideal self-presentation. Respondents with higher self-esteem were claimed to have less desire to present themselves in an idealized way on Tinder because of their high confidence in their actual look. Besides that, false selfpresentation was found among respondents who were less educated users and had low selfesteem.

Some studies suggested that a non-edited view of self and the gap between the ideal self and real self can decrease self-esteem (Gonzales \& Hancock, 2011; Michikyan et al., 2014). This shows that individuals with low self-esteem are not confident and satisfied with their true selves. Therefore, devaluation of self happens when they see their non-edited, true self.

This was supported by the study carried out by Gonzales and Hancock (2011). In their study to identify the effects of exposure to Facebook on self-esteem, they conducted a survey among 63 students ( 16 males, 47 females) from a large, Northeastern University. The findings stated that the exposure to information presented on Facebook profiles enhanced selfesteem, especially when the respondent edited their information presented. On the other hand, a non-edited view of the respondents was likely to decrease their self-esteem. Therefore, Gonzales and Hancock (2015) suggested that self-esteem could be improved if online self-presentation was given extra care.

To examine the relationship between self-presentation and peer comparison on social media in the context of beauty, Chua and Chang (2016) carried out 24 in-depth interviews with secondary students in Singapore. From the study, they proved that edited selfpresentation happened among teenage girls in Singapore because of the feelings of low selfesteem and insecurity. They believed that it was necessary to edit their photographs to perfection. This phenomenon was driven by the desire to gain attention, validation, and recognition from their peers.

Furthermore, research showed that people with low self-esteem used Facebook differently from those with higher self-esteem. In a study conducted by Tazghini and Siedlecki (2013), 201 young adults aged around 17 to 29 were studied to examine Facebook use and its relationship to self-esteem. From the study, they found out that those with lower self-esteem tend to "un-tag" undesirable photos of themselves on Facebook more frequently. Tazghini and Siedlecki presumed that the act of "un-tagging" undesirable photos aimed to preserve their images.

In short, high self-esteem individuals presented themselves authentically because they were confident with their true selves. On the other hand, low self-esteem individuals tended to present themselves selectively or deceptively. Some suggested that it was a defense mechanism for low self-esteem individuals because they were not satisfied and confident with their true selves. Therefore, they tended to edit their photographs and information as well as "un-tagging" unwanted photographs to preserve their images.

In Malaysia, for self-esteem, most of the researchers studied the relationship between self-esteem and academic performance, stress, and health among university students. There is not much research related to online self-presentation among university students. A relevant study was carried out in 2016 on online self-presentation among university students in Malaysia in terms of textual context. It was "Online Self-Presentation and Impression 
Management (SPIM) among Malaysian Tertiary Level Students on Facebook" by (Husnita et al., 2016).

Therefore, this qualitative study was carried out to study how university students express their self-esteem and manage their visual self-presentation on Facebook, including the reasons behind it, to fill the academic gap in understanding the self-esteem and selfpresentation in the virtual world.

\section{Methodology}

The research design used in this study was descriptive research to describe the selfesteem, visual self-presentation as well as the relationship between both variables among undergraduate students in a public university in Malaysia. Besides that, phenomenological research was used to find out the reasons for different types of visual self-presentation on Facebook among students based on their life experiences.

For this study, the sample size was determined using the saturation method. Openended questions were asked based on the research questions. The interview sessions stopped when there were no new ideas or data can be obtained, especially when the data are repetitive. A total of ten individuals were selected by using purposive sampling based on the predetermined criteria and characteristics, i.e., Chinese students of different genders, 19 to 24 years old, owned Facebook accounts, and actively posted photographs or videos on Facebook profiles three months before the research. Content analysis was used to interpret the data collected in the interviews. Three steps of coding were used in this study, which were open coding, axial coding and selective coding.

\section{Findings and Discussion \\ Self-esteem in Facebook Use}

The level of self-esteem in this part was discussed in the context of Facebook use. Three behaviors related to Facebook usage were identified to determine the level of selfesteem of the informants. The self-esteem expressions of the students were discussed in the level of high self-esteem and low self-esteem.

\section{High Self-esteem}

Informants with high self-esteem were not Facebook addicted. Besides that, they accepted more real-life or known friends on Facebook. When there were unflattering photographs on their Facebook profiles, they would not "un-tag" the photographs.

\section{Not addicted to Facebook}

Informants with high self-esteem spent less than two hours daily. Most of them used this time to check friends' statuses, read the news and chat with friends. Informant C, E, G, I, and J indicated this respectively: "less than one hour. I check the homepage to see if there is something new, funny, and interesting."; "around 1 hour. I check friends' statuses and read the news."; "I spend around one to two hours on Facebook for non-work-related reasons. I usually use these two hours to check my friends' statuses and check the latest news and trends."; and "around one to two hours. I read news, check friends' posts and statuses, chat with friends." 


\section{Accepted more real-life/known Friends}

Besides that, informants with high self-esteem tended to have more real-life or known friends on their Facebook. Most of them did not add or accept strangers on their Facebook. They did not like strangers to know their statuses from Facebook. Therefore, they were careful in adding and accepting friends on Facebook. For example, informant C said, "I have more real-life friends. I have not more than ten strangers on my Facebook because I do not like strangers to see my statuses and posts. I will choose very carefully before I accept any friend requests." Informant F expressed, "I have more real-life friends because I don't simply add and accept strangers. I do not like to see strangers' posts and I do not like my statuses and photos to be seen by strangers as well. That's why I avoid adding strangers." The same idea was also shared by informants $D, E$, and $I$.

\section{Would not "un-tag" Unflattering Photographs}

Informants with high self-esteem would not "un-tag" their unflattering photographs. Some of them would take some actions but not "un-tag" or delete the photographs. They would leave the unflattering photographs on their Facebook to be seen by others. Informants E and F said, "I will do nothing. I do not care about that" and "I will do nothing. I do not mind because I think that beautiful or ugly photo is not very important" respectively. Their views were agreed upon by informant $G$ and $I$. Meanwhile, informant $D$ expressed that she would only grumble in her heart when she saw the unflattering picture. She said, "I will be unhappy. I will grumble in my heart but I would not delete or "un-tag" the pictures."

\section{Low Self-esteem}

In contrast to the high self-esteem behavior, low self-esteem informants expressed that they were Facebook addicted. Besides that, they accepted more strangers on Facebook. They would "un-tag", delete or "hide" the unflattering photographs of them on Facebook.

\section{Facebook Addicted}

Informants who were low self-esteem spent more than two hours per day on Facebook for non-work-related reasons. They spent time on Facebook chatting with friends, playing games, watching videos, and checking on others' statuses. Most of them spent around three to five hours on Facebook for non-work-related reasons. Informant A, B, H, and J were among the informants who stated that they spent more time on Facebook. Informant $A$ said, "I think 4 to 5 hours per day. I read through the news feed on my homepage and keep on refreshing and repeating." Informant B said, "I spend more than 3 hours checking my friends' statuses and update the Facebook homepage. Sometimes, I play Facebook games and chat with friends through Messenger." Informant H indicated, "Three to four hours. I will watch videos and others' status" while informant J told, "I spend around 10 hours to see new feeds and my friends' posts on my Facebook homepage."

\section{Accepted more Strangers on Facebook}

Informants with low self-esteem tended to accepted more strangers than real-life friends on Facebook. However, most of them accepted a lot of strangers when they first used Facebook. This might not be related to the low self-esteem but the curiosity when they first used Facebook. Only one informant mentioned that she had more strangers on Facebook because she did not have a lot of friends in real life. For instance, informant A said, "I think strangers. When I first play Facebook, I wish to know more friends. Therefore, I accept a lot 
of strangers or friends of friends." Informant B expressed that, "I think I have more strangers in my Facebook friend list. This is because I accepted whoever when I first use Facebook." And informant J said, "strangers are more than real-life friends. I just simply accept friend requests when I started to use Facebook."

\section{"Un-tag", Hide or Delete Unflattering Photographs}

Those who were low self-esteem would "un-tag", hide, or delete the unflattering photographs that could be found on their Facebook profile. They did not want others to see their ugly photographs. They would take some actions to protect their image on Facebook. This expression was found in informant A and J. Informant A said, "I will hide it from my timeline actually. I do not want my friends to see the ugly photos of mine." While informant J stated, "I will hide the tag. I want to protect my image. I do not want my Facebook friends to see my ugly photos."

In short, the self-esteem of the informants was expressed in terms of Facebook use. According to research to determine the relationship between Facebook addiction, selfesteem, and life satisfaction that was carried out by Blachnio et al (2015), Facebook addiction was related to lower self-esteem. Besides that, people with low self-esteem accept more friend requests from strangers and frequently "un-tagging" unflattering pictures on Facebook (Tazghini \& Siedlecki, 2013). On the other hand, individuals with high self-esteem are not Facebook addicted, accept more known friends, and will not "un-tag" unflattering pictures on Facebook.

The results were consistent for most of the informants. They showed both high selfesteem in self-description and Facebook context and some were the other way round. However, some informants showed inconsistency. For this circumstance, most of them were high self-esteem in self-description but low self-esteem in the Facebook context.

\section{Visual Self-Presentation on Facebook}

The ways of managing visual self-presentation on Facebook were divided into two categories in this part. The two categories are selective visual self-presentation and authentic visual self-presentation.

\section{Selective Visual Self-Presentation}

Selective visual self-presentation was used by the informants on Facebook. They selected and edited the photographs and videos before they posted them on Facebook.

Informants had different concerns and preferences in selecting the photographs and videos to be posted on Facebook. Most of them chose nice, beautiful, and memorable photographs to be posted on Facebook. For instance, when the informants were asked "how do you select the photographs or videos to be posted on Facebook?" informant A said, "I will make sure that the photos are nicely taken. I want the photos to be perfect. Therefore, I will choose photos with a nice and clean background. Most importantly, I need to look nice in the photos."; informant B said, "I will choose those I think it is nice so that all the photographs I post on Facebook are nice and beautiful."; and informant E said, "I will choose and good quality photos as well memorable photos."

There was also an informant who preferred group photographs. Informant I said that "I prefer group photos where everyone is there." In addition, an informant cared about the quality of the photographs, especially the lighting. Informant J said, "For the photo, I will choose the one with the great lighting. For video, I will choose the one with funny contents." 
Informants also edit their photographs before uploading them to Facebook. They usually edit the filters, colors, brightness, saturation, and effects of the photographs. Most of them use mobile applications such as Meitu XiuXiu, B612, and SNOW to edit the photographs. They edit their photographs for several reasons.

Firstly, to look better in photographs. For instances informant A said, "Yes, I do edit my photos. I use Meitu Xiu Xiu to edit the filters and crop the photos. I also use Snapseed to edit scenery photos. Normally I will adjust the brightness and the saturation of the photos. I also use apps that provide cute face filters like SNOW. I want to look better in a photo."

Informant B also shared a similar statement, she said,

"Yes, I edit my photographs before posting on Facebook. I usually edit the filter of the photos so that the photos look nicer and prettier. Sometimes, filters are very important to show the beauty of the photos. I use applications such as Meitu, Snapseed, and VSCO to edit my photographs."

Secondly, to protect the image. As informant $C$ said that, "I edit the filters. I use mobile applications such as B612, Snow, and Foodie to edit my photos. Since the technology is improving, we do not need professional software like Photoshop to edit our photos. I want to look beautiful and protect my image."

Thirdly, to enhance the beauty and quality of the photographs. Informants $E$ and $F$ admitted that "Yes. I use Meitu and Instagram filters to edit my photos. I edit my photos because I want to beautify them."; "I will edit. I will edit the filters and colors but not the parts of my body. I will ask my friends to recommend to me some applications to edit photographs. I want my photos to be more beautiful. In addition, lack of confidence is another reason." Similar reasons were also shared by the rest of the informants.

\section{Authentic Visual Self-Presentation}

Informants who used authentic visual self-presentation presented their true selves on Facebook. They did not edit their photographs before they uploaded them to Facebook.

The informants who upload non-edited photographs to Facebook. Informants who used authentic visual self-presentation did not edit their photographs before uploading them to Facebook. Informant $D$ reasoned that it was unnecessary since her Facebook friends were her real-life friends who knew her well. She said, "No. I think it is not necessary. My Facebook friends are all those around me. They know how I look." While informant $\mathrm{H}$ suggested that it was unnecessary because we all looked beautiful in God's creation. He said, "No. I think we all look beautiful in God's creation. Everyone should be unique. Therefore, we don't have to edit our photo."

Overall, the majority of informants used selective visual self-presentation on Facebook. They selected and edited the photographs they uploaded on Facebook. Most of them edited the filters, brightness, color, and effect of the photographs. They used mobile applications such as Meitu XiuXiu, B612, VSCO, Instagram, and SNOW to edit their photographs.

From the data, the informants could be said that they behave differently depending on the presence of the audience. For those who had more strangers on Facebook friend list, they tended to edit their photographs. Besides that, most of the informants used selective 
visual self-presentation on Facebook. This was also parallel to Walther's Hyperpersonal Model that stated that selective self-presentation was possible because of the time lag in the virtual world (Walther, 1996). Because of the time lag, the informants selected their photographs and videos to be uploaded to Facebook according to their preference. They even had the time to edit the photographs before posting.

Besides that, the results could be related to the level of acceptance of the informants on editing photographs. All of the informants who used selective visual self-presentation accepted themselves to edit their photographs. They did not think it was something weird and unacceptable. In their opinion, photographs could be nicer and prettier after editing. Informant A said that "I can accept but depends on the ways of editing. Sometimes the photos can be nicer after editing." Informant B said, "Yes, I can accept it as long as it is not too over. I think we all have the right to look beautiful." Informant F said, "I think it is acceptable if I only edit a little bit. I accept because I would like my photos to look nicer." And Informant G said, "I am okay with that. I don't have strong feelings about that as long as others can still recognize me. Besides that, I think it is quite normal to edit photos."

Furthermore, one informant suggested that editing photographs showed that one put the effort into the photographs. Informant J said, "Why not? Editing photo and video show that you respect the photographs. It also shows how much effort you put in them."

Generally, the informants used selective visual self-presentation to show their good part on Facebook. They wanted to present the nice, beautiful and perfect part of them on Facebook.

\section{Conclusion}

For the description of self-esteem on Facebook, informants that showed high selfesteem were not addicted to Facebook, accepted more known friends, and did not "un-tag" unflattering photographs on Facebook. Those with low self-esteem were Facebook addicted, accepted more strangers, and frequently "un-tag" unflattering pictures on Facebook. For the management of visual self-presentation, most of the informants used selective visual selfpresentation on Facebook. They selected the photographs they wanted to upload on Facebook according to their preferences. Besides that, they edited their photographs before posting them to Facebook. They insisted that only filters, colors, brightness, and effects of the photographs were edited. They did not edit any parts of their physical appearance.

The reasons for selective visual self-presentation on Facebook were discussed. It was parallel to Goffman's Self-Presentation Theory that stated that individuals behaved differently due to the presence of the audiences. The informants edited their photographs since there were strangers and friends on their Facebook. Besides that, it was parallel to Walther's Hyper-personal Model (Walther, 1996). The informants were able to use selective visual self-presentation because of the time-lag in a virtual world. They had enough time to select and edit their photographs. Furthermore, the level of acceptance of editing photographs was high among the informants. Due to several reasons, they edited their photographs. They accepted themselves editing the photographs. Some stated that it was normal to edit photographs.

The research results provide a big picture for relevant authorities on the characteristics of low and high self-esteem as well as the trends of self-esteem among university students, especially in the virtual world. With the knowledge of self-esteem, a lot of problems could be minimized or eliminated because the relevant authorities could come up with efficient solutions. For instance, low self-esteem university students were identified. 
Since some of the commit suicide cases were caused by low self-esteem, it could be prevented by organizing programs to boost the self-esteem among university students.

This research focused only on photographs and videos uploaded on Facebook. Besides that, the research focused only on Chinese students. Therefore, possible areas for future researches are to include other social networking sites besides Facebook such as Instagram, Snapchat and Twitter and to involve different ethincity for comparison. Besides that, future researches may include other self-presentations such as textual self-presentation and online self-presentation too.

\section{References}

Blachnio, A. P. (2016). Association between Facebook addiction, self-esteem and life. Computers in Human Behavior, 55, 701-705. doi:https://doi.org/10.1016/j.chb.2015.10.026

Brown, V. (2017). Cyberbullying: Words can hurt too. The Star Online. https://www.thestar.com.my/news/nation/2017/10/19/cyberbullying-words-canhurt-too/

Chua, T. H., \& Chang, L. (2016). Follow me and like my beautiful selfies: Singapore teenage girls' engagement in self-presentation and peer comparison on social media. Computers in Human Behavior, 55, 190-197. doi:https://doi.org/10.1016/j.chb.2015.09.011

Gil-Or, O., Levi-Belz, Y., \& Turel, O. (2015). The "Facebook-self": characteristics and psychological predictors of false self-presentation on Facebook. Frontiers in Psychology, 6(99), 1-10. doi: https://doi.org/10.3389/fpsyg.2015.00099

Girl's True Self Revealed. (2017). SOHU News. https://www.sohu.com/a/193500598_267097 Gonzales, A. L., \& Hancock J. T. (2011). Mirror, Mirror on my Facebook Wall: Effects of Exposure to Facebook on Self-Esteem. Cyberpsychology, Behavior, and Social Networking, 14(1-2), 79-83. doi:10.1089/cyber.2009.0411

Husnita, H. Y., Tan, K. H., \& Saadiyah D. (2016) Online self-presentation and impression management (SPIM) among Malaysian tertiary level students on Facebook. Evolution in Language Studies. 36-55.

Kim, Y., \& Baek, Y. M. (2014). When is Selective Self-Presentation Effective? An Investigation of the Moderation Effects. Cyberpsychology, Behaviour, and Social Networking, 17(11), 697-701. doi:10.1089/cyber.2014.0321

McDonough, M. (2014). Catfishing - Fake Online Profiles and Their Effects on Others. Everwood Day Camp. http://everwooddaycamp.com/catfishing-fake-online-profileseffects-others/

Michikyan, M., Dennis, J., \& Subrahmayam, K. (2014). Can You Guess Who I Am? Real, Ideal and False Self-Presentation on Facebook Among Emerging Adults. Emerging Adulthood, 3(1), 55-64. doi:https://doi.org/10.1177/2167696814532442

Pillay, S. (2017). Suicide on the rise among Malaysian youth. New Straits Time. https://www.nst.com.my/news/exclusive/2017/05/243354/suicide-rise-amongmalaysian-youth

Ranzini, G., Lutz, C., \& Gouderjaan, M. (2016). Swipe Right: An Exploration of Self-Presentation and Impression Management on Tinder.

https://www.alexandria.unisg.ch/publications/248333

Shaari, A. H., Kamaluddin, M. R., Paizi@Fauzi, W. F., \& Mohd, M. (2019). Online-Dating Romance Scam in Malaysia: An analysis of online conversations between scammers 
and victims. GEMA Online ${ }^{\circledR}$ Journal of Language Studies, 19(1), 97-115. http://doi.org/10.17576/gema-2019-1901-06

Tazghini, S., \& Siedlecki, K. L. (2013). A Mixed-Method to Examining Facebook Use and Its Relationship to Self-Esteem. Computers in Human Behavior, 29, 827-832. http://dx.doi.org/10.1016/j.chb.2012.11.010

Vijaindren, A. (2017). Love scam: Spinning a web of deceit. New Straits Time. https://www.nst.com.my/news/exclusive/2017/06/247760/love-scam-spinningweb-deceit

Walther, J. B. (1996). Computer-mediated communication: Impersonal, interpersonal, and hyperpersonal interaction. Communication Research, 23(3), 3-43.

doi:10.1177/009365096023001001 